\title{
http://dx.doi.org/10.21611/qirt.1994.025 \\ Comparative application of two infrared scanners to heat transfer measurements in a Mach 6 wind tunnel.
}

\author{
by CHARBONNIER M. J., LAPOSTOLLE S. and SIMEONIDES G.
}

von Karman Institute for Fluid Dynamics, Chaussée de Waterloo 72, B-1640 Rhode-StGenèse, Belgium.

\begin{abstract}
The performances of two infrared scanning radiometers (Inframetrics 525 \& Agema 900 systems) used in the VKI H-3 Mach 6 wind tunnel are presented and discussed. The spatial resolution characteristics of the two scanners are evaluated using in-house calibrations. Modelling of the SRF and MTF are validated against measurements. Finally, a restoration technique based on the MTF response is applied for the quantification of the striation heating on a compression ramp in hypersonics.
\end{abstract}

\section{Introduction}

Quantitative infrared thermography has been implemented in recent years in the Mach $6 \mathrm{H}-3$ wind tunnel of the von Karman Institute as the main heat transfer measurement technique. The $\mathrm{H}-3$ wind tunnel and the implementation of the infrared thermography technique, originally making use of an Inframetrics 525 infrared scanning radiometer, have been discussed previously in [1-5]. It was then demonstrated that heat transfer distributions deduced from temperature mapping of the models by applying the semi-infinite slab principle after [6], exhibited a similar degree of quality as those measured with more classical instrumentation.

Recently, the Inframetrics 525 scanning radiometer has been replaced by an Agema 900 scanner (both operating in the Long Wave range $8-12 \mu \mathrm{m}$ ), exhibiting a higher thermal resolution and dynamic range, and a straightforward digital image acquisition capability which allows for the use of an updated Digital Image Processing (DIP) system and data reduction procedure.

In the subsequent discussion the performances of the two measurement systems will be compared on the basis of the manufacturers' specifications on the performance characteristics of the two scanning radiometers but, moreover, with the aid of in-house performed calibrations for the thermal and spatial resolution of the complete measurement chains in the actual experimental set-up configuration. The spatial resolution will be supported by the example of results obtained in regions of shock wave boundary layer interaction over two-dimensional flat plate / compression ramp configuration in hypersonics.

\section{Performance characteristics and calibration of the two measurement systems}

\subsection{System sensitivity and measurement range}

The maximum thermal sensitivity of the Inframetrics 525 scanner is specified by the manufacturer to $0.2 \mathrm{~K}$, and a selection of nominal (i.e. with no signal attenuation due to, say, finite surface emissivity or transmissivity of the viewing window) full scale ranges $(10,20,50$, 100 and $500 \mathrm{~K}$ ) is offered which are all resolved by the scanner into 64 grey levels and, eventually, by the associated DIP system into 256 intensity levels. The Inframetrics measurement system has been employed in the $\mathrm{H}-3$ tunnel using linear temperature-intensity calibration curves measured in situ [5] which integrate both the model emissivity and the tunnel window transmissivity. A typical calibration uncertainty band indicates a conservativo calibration uncertainty level of $\pm 2 \%$ of the full scale, whereas the Noise Equivalent Temperature Difference (NETD) or thermal resolution of the system is of the order of $0.3 \mathrm{~K}$ for the tele lens (Field Of View $6^{\circ}$ horizontal $\times 4.5^{\circ}$ vertical) and $0.5 \mathrm{~K}$ for the standard lens (FOV $\left.18^{\circ} \times 14^{\circ}\right)$. 
For the Agema 900 system, the maximum thermal sensitivity specified in the technical documentation is $0.08 \mathrm{~K}$. The detector output is digitized into 4096 levels $(0.027 \mathrm{~K} /$ intensity level) and the NETD is estimated to $0.05 \mathrm{~K}$ in the range of absolute temperature currently used $(243 \mathrm{~K}-353 \mathrm{~K})$. The high thermal sensitivity on a large temperature band $(110 \mathrm{~K})$ allows for . measurements over regions with rapidly varying heat transfer rate as encountered on the flat ${ }^{\circ}$ plate / ramp in hypersonics.

Non-linear temperature / intensity calibration curves are provided by the manufacturer for the $20^{\circ} \mathrm{H} \times 10^{\circ} \mathrm{V}$ and the $10^{\circ} \mathrm{H} \times 5^{\circ} \mathrm{V}$ optics. The Agema software uses these calibrations to compute the temperature taking into account the emissivity of the body and the atmospheric transmissivity. An example of a calibration made in situ in the $\mathrm{H}-3$ tunnel to evaluate the emissivity $\varepsilon$ of the calibration plate and the transmissivity $\tau$ of the tunnel germanium window is given in fig. 1. By setting the emissivity and transmissivity to 1 in the software parameter list, the thermal values displayed by the Agema software are not corrected for the ambient and atmospheric contributions and correspond to the flux $I_{m}$ received by the detector (eq. 1).

$$
I_{m}=I\left(T_{\text {Plate }}\right) \cdot \tau \cdot \varepsilon+\tau \cdot(1-\varepsilon) \cdot I\left(T_{a m b .}\right)+(1-\tau) \cdot I\left(T_{\text {atm. }}\right)
$$

On the other hand, the temperature of the calibration plate $T_{\text {Plate }}$ measured by thermocouples allows to integrate the Planck's law in the infrared band $8-12 \mu \mathrm{m}$ in order to obtain the flux of the equivalent black body. In order to extract the values of $\varepsilon$ and $\tau$, the initial value is subtracted to eliminate the ambient and atmospheric contributions which are assumed to remain constant during the calibration.

$$
I_{m}-I_{\text {Initial }}=\left(I\left(T_{\text {Plate }}\right)-I\left(T_{\text {Platelnitial }}\right)\right) \cdot \tau \cdot \varepsilon
$$

Assuming the atmospheric transmissivity equal to 1 (small operating distance in dry air), the calibration plate emissivity estimated using the data measured without the germanium window is $\varepsilon=0.979 \pm 0.02$. Using the intensity recorded through the germanium window, the window transmissivity is then estimated to $\tau=0.821 \pm 0.008$. These two parameters are used in combination with the scanner calibration to obtain the model temperature increase during the tests in the $\mathrm{H}-3$ wind tunnel.

\subsection{Spatial resolution and measurement domain}

The spatial resolution of the infrared scanner is primarily determined by the Instantaneous Field Of View (IFOV) defined as the solid angle substented by the detector through the optical system. It is therefore a function of both the detector size and the scanner optics. As a rule of thumb, significant attenuation due to the scanner's spatial resolution may be anticipated when sharp surface temperature variations occur over viewing angles smaller than 5-10 times the IFOV. Actually, the spatial resolution of a scanner is often characterized by the angle $\alpha_{1 / 2}$ corresponding to the SRF value of $50 \%$.

Concerning the Inframetrics 525 scanning radiometer, $\alpha_{1 / 2}$ is equal to $2 \mathrm{mrd}$ in the case of the standard lens $\left(18^{\circ} \times 14^{\circ} \mathrm{FOV}\right.$, i.e. approximately $32 \mathrm{~cm} \times 24 \mathrm{~cm}$ for a typical $1 \mathrm{~m}$ operating distance from the model surface) and to $0.7 \mathrm{mrd}$ in the case of the $3 x$ tele lens (approximately $10 \mathrm{~cm} \times 8 \mathrm{~cm}$ at $1 \mathrm{~m}$ distance). For the typical operating distance of $1 \mathrm{~m}$ from the model surface, these angles translate to $2 \mathrm{~mm} \times 2 \mathrm{~mm}$ and $0.7 \mathrm{~mm} \times 0.7 \mathrm{~mm}$ for the standard and tele lenses, respectively.

For the Agema 900 scanner, $\alpha_{1 / 2}$ is equal to $1.5 \mathrm{mrd}$ for the standard lens $\left(20^{\circ} \times 10^{\circ}\right)$ (approximately $35 \mathrm{~cm} \times 17.5 \mathrm{~cm}$ at $1 \mathrm{~m}$ operating distance) and $0.76 \mathrm{mrd}$ for the $10^{\circ} \times 5^{\circ}$ lens (approximately $17.5 \mathrm{~cm} \times 9 \mathrm{~cm}$ at $1 \mathrm{~m}$ operating distance). These give, at $1 \mathrm{~m}$ operating distance, areas of $1.5 \mathrm{~mm} \times 1.5 \mathrm{~mm}$ and $0.76 \mathrm{~mm} \times 0.76 \mathrm{~mm}$ respectively. It is clear that the spatial resolution characteristics of the Agema infrared camera are superior to the ones of the older Inframetrics camera since, for the standard lens operation, it has a smaller $\alpha_{1 / 2}$ for a similar FOV.

A more systematic way to characterize the spatial resolution of infrared scanning radiometers is by considering the Slit Response Function (SRF) and Amplitude Modulation Factor (AMF) of the scanner with the entire measurement chain. The former corresponds to the system response to a "slit" surface temperature variation, and the latter to the system response to a periodic (square wave) surface temperature distribution. Actually, the AMF is the 
http://dx.doi.org/10.21611/qirt.1994.025

maximum amplitude of the response normalized by the amplitude of the original square wave signal. The extension of this definition to a sinusoidal signal would lead to the so-called Modulation Transfer Function (MTF) which is impossible to simulate experimentally. The calibrated SRF and AMF functions of the two measurement systems are compared in fig. 2 \& 3. For the Agema system, the SRF and AMF are only measured for the standard lens. As seen in fig. 2, the Agema 900 system is superior to the Inframetrics 525 system with the standard lens (for similar measurement domains), moreover it has an SRF response close to the SRF response of the Inframetrics with the tele lens. The AMF response of the Agema scanner with the standard lens is between the AMF measured for the Inframetrics with the standard and tele lenses. It again indicates a higher spatial resolution for the Agema 900 compared to the Inframetrics 525.

A procedure to model the MTF curve of a given measurement system has been proposed by De Lucas et al in [7]. It is based on the principle that the impulse response of the system is of Gaussian type. Thus it leads to the following expression of the SRF:

$$
\operatorname{SRF}(\alpha)=\operatorname{erf}(\alpha / 2 \sigma)
$$

where erf is the error function, $\alpha$ is the slit aperture and $\sigma=\alpha_{1 / 2} / 0.96$ is the shape parameter.

The measurement of the SRF curves allows to compute $\sigma$ using $\alpha_{1 / 2}$ as seen in fig. 4 where the measured SRF is compared with the model. The modelisation is in perfect agreement with the experiment for both the scanning of horizontal (fig. 4) and vertical slits. Since the MTF is the Fourier transform of the impulse response, it gives after [7]:

$$
\operatorname{MTF}(v)=\exp \left(-\pi^{2} \bar{\sigma}^{2} v^{2}\right)
$$

where after [7], $\bar{\sigma}=\sigma\left(1+\frac{1+\beta^{2}}{6\left(\sigma f_{s}\right)}\right)^{1 / 2}$ with $\beta=0.035$ and the sampling frequency $f_{s}=0.78 m r d^{-1}$

Using the values of $\sigma$ determined above for the $20^{\circ} \times 10^{\circ}$ optics, the MTF is modelled for both horizontal and vertical sinusoidal waves. Based on the MTF, the restoration proposed in [8] can be applied to correct the measurements when scanning the row of slits used in the measurement of the AMF. Using the Fourier transform of the square wave signal applied, the output of the camera is predicted by applying the MTF response and compared to the measured AMF. Figures $5 \& 6$ display the measured and predicted AMF curves and the predicted MTF curve for horizontal and vertical slits. Clearly the very good agreement between the predicted and measured AMF for both slit directions validates the MTF model of eq. 4 . Then the predicted MTF for horizontal waves will be used to correct for limited spatial resolution in the detection of the striation heating data on the compression ramps.

\subsection{Time resolution and total acquisition time}

The time resolution of an infrared scanner is determined by the scanning frequency of the optical mirrors/prisms used to focus a series of IFOVs over the measurement domain onto the single infrared detector.

The Inframetrics 525 output signals are produced at a video-compatible framing rate of 25 $\mathrm{Hz}$ as data acquisition is performed on a video recorder before the data are digitized and transferred to the computer DIP system. Noting that a frame is produced by the interlacing of two consecutive fields, each acquired at $50 \mathrm{~Hz}$, it results in an uncertainty in the definition of the time of $\pm 10 \mathrm{~ms}$ if a single time is allocated to each field. The Inframetrics system is also capable of a line scan operation mode, whereby one single line is repeatedly scanned in each field. The acquisition frequency is then increased to $7.87 \mathrm{kHz}$ and the time uncertainty I variation along each line is $\pm 0.06 \mathrm{~ms}$. Clearly, the video acquisition of the output signals imposes virtually no restriction on the total data acquisition time.

The Agema output signals are directly recorded in digital form on a personal computer at a (non-interlaced) framing rate of either $15 \mathrm{~Hz}$ or $30 \mathrm{~Hz}$. Consequently, the best time resolution of the system is $33 \mathrm{~ms}$. It is noted, however, that in the $30 \mathrm{~Hz}$ image acquisition mode the vertical FOV is reduced by a factor of 2 in order to maintain compatibility with the digital line acquisition rate. In a line scan operation the line acquisition frequency is increased to $2.5 \mathrm{kHz}$. The 540 megabyte disk storage available with the system's PC allows for a total acquisition 
http://dx.doi.org/10.21611/qirt.1994.025

time up to 10 minutes. After a first reduction with the Agema software, the data files are transferred using the network on the VKI computers for further data analysis.

\subsection{Comparative performance summary}

The following table summarizes the characteristics of the two infrared scanning radiometers.

\begin{tabular}{|c|c|c|c|c|}
\hline Characteristics & \multirow{2}{*}{\multicolumn{2}{|c|}{$\begin{array}{c}\text { Inframetrics } 525 \\
\text { video signal } \\
\text { field rate }: 50 \mathrm{~Hz} \text { interlaced } \\
\text { frame rate: } 25 \mathrm{~Hz} \\
\text { Line scan: } 7.87 \mathrm{kHz}\end{array}$}} & \multicolumn{2}{|c|}{ Agema 900} \\
\hline Time resolution & & & $\begin{array}{l}\text { digita } \\
\text { non-interlaced, } \\
\text { / } 30 \mathrm{~Hz} \\
\text { Line scan: } 2.5\end{array}$ & $\begin{array}{l}\text { gnal } \\
\text { ame rate : } 15 \\
z\end{array}$ \\
\hline Optics & $18^{\circ} \mathrm{H} \times 14^{\circ} \mathrm{V}$ & $6^{\circ} \mathrm{H} \times 4.5^{\circ} \mathrm{V}$ & $20^{\circ} \mathrm{H} \times 10^{\circ} \mathrm{V}$ & $10^{\circ} \mathrm{H} \times 5^{\circ} \mathrm{V}$ \\
\hline $\begin{array}{c}\text { Field Of View at } 1 \mathrm{~m} \\
\text { distance }\end{array}$ & $32 \times 24 \mathrm{~cm}^{2}$ & $10 \times 8 \mathrm{~cm}^{2}$ & $35 \times 17.5 \mathrm{~cm}^{2}$ & $17.5 \times 9 \mathrm{~cm}^{2}$ \\
\hline Temperature Range $\Delta \mathrm{T}$ & \multicolumn{2}{|c|}{$10,20,50,100,500 \mathrm{~K}$} & \multicolumn{2}{|c|}{$110,250,500,1200 \mathrm{~K}$} \\
\hline $\begin{array}{l}\text { Maximum thermal } \\
\text { sensitivity }\end{array}$ & \multicolumn{2}{|c|}{$0.2 \mathrm{~K}$} & \multicolumn{2}{|c|}{$0.08 \mathrm{~K}$} \\
\hline $\begin{array}{l}\text { Uncertainty on temp. } \\
\text { measurement }\end{array}$ & \multicolumn{2}{|c|}{$\begin{array}{c} \pm 2 \% \text { full scale } \\
\text { (for relative temp. measurement) }\end{array}$} & \multicolumn{2}{|c|}{$\begin{array}{c} \pm 1 \% \text { full scale } \\
\text { (for absolute temp. measurement) }\end{array}$} \\
\hline NETD & \multicolumn{2}{|c|}{$0.5 / 0.3 \mathrm{~K}$} & \multicolumn{2}{|c|}{$0.05 \mathrm{~K}$} \\
\hline Spatial resolution & FOV $18^{\circ} \times 14^{\circ}$ & FOV $6^{\circ} \times 4.5^{\circ}$ & FOV $20^{\circ} \times 10^{\circ}$ & FOV $10^{\circ} \times 5^{\circ}$ \\
\hline SRF $=50 \%$ (tech. specif.) & $2 \mathrm{mrd}$ & $0.7 \mathrm{mrd}$ & $1.5 \mathrm{mrd}$ & $0.76 \mathrm{mrd}$ \\
\hline AMF $=90 \%$ (measured) & $\begin{array}{l}22.5 \mathrm{mrd} \\
\pm 2.5\end{array}$ & $\begin{array}{l}7.5 \mathrm{mrd} \\
\pm 1.5\end{array}$ & $\begin{array}{l}7.5 \mathrm{mrd} \\
\pm 0.5\end{array}$ & 1 \\
\hline AMF=50\% (measured) & $\begin{array}{c}8 \mathrm{mrd} \\
\pm 1\end{array}$ & $\begin{array}{l}2.7 \mathrm{mrd} \\
\pm 0.3\end{array}$ & $\begin{array}{l}4.5 \mathrm{mrd} \\
\pm 0.35\end{array}$ & I \\
\hline
\end{tabular}

Table 1. - Summary of the performances

\section{Application to the striation heating studies}

Application of infrared thermography to extensive investigations of the shock wave boundary layer interaction phenomena over two-dimensional flat plate / compression ramp configurations have been undertaken in the $\mathrm{H}-3$ wind tunnel in recent years [2,3]. Emphasis in these studies has been placed on transitional flows, whereby laminar-turbulent transition is promoted in the reattachment flow region on the deflected ramp with the aid of the disturbance amplification mechanisms. It gives rise to the formation of streamwise Taylor-Görtler vortices, the footprint of which is manifested in the form of closely spaced streamwise heating striations developing along the deflected ramp.

Typical spanwise heat transfer distributions on the deflected ramp exhibit characteristic wave lengths of about $3 \mathrm{~mm}$. Such striations were measured with the Agema scanner with both optics and the restoration procedure based on the MTF function $[7,8]$ was applied (for MTF values greater than $10 \%$ to avoid amplification of the noise). The typical striation wavelength corresponds to a spatial frequency of about $4.5 \mathrm{mrd}^{-1}$ for which the MTF coefficient is close to 0.65 for the $20^{\circ} \times 10^{\circ}$ optics (fig. 5). The raw and restored temperature signals across the striations plotted in fig. 7 shows a moderate correction of the peak amplitude for this lens. Since no characterization of the $10^{\circ} \times 5^{\circ}$ optics was done, the ratio of the two FOV is used to deduce the MTF of this lens from the MTF coefficient of the standard lens (it has been shown that this rule applies for the Inframetrics, fig. 3, [5]). Figure 8 clearly shows that, using the $10^{\circ}$ 
http://dx.doi.org/10.21611/qirt.1994.025

$\times 5^{\circ}$ optics, the limited spatial resolution effects are negligible and the only effect of the restoration is to reveal small peaks of higher spatial frequencies.

\section{Concluding remarks}

An Inframetrics 525 and an Agema 900 infrared scanner: are compared in their application to quantitative heat transfer measurement in a Mach 6 wind tunnel. As expected since the Inframetrics 525 system is about 15 years old, the level of performance of the Agema 900 system is found superior as far as thermal and spatial resolutions are concerned.

The SRF and MTF models proposed by De Luca et al [7] are validated against experimental data for temperature waves perpendicular and parallel to the horizontal scanning direction. Moreover the application of the MTF model provides a very good prediction of the measured AMF curve resulting from the response of the system to a square wave temperature signal.

Finally, the application of the Agema 900 scanner to the study of striation heating on compression ramps in hypersonics is shown to be very promissing since the correction applied by the restoration method using the MTF remains very limited while keeping a quite large field of view on the model $(10 \mathrm{~cm} \times 5 \mathrm{~cm})$.

\section{REFERENCES}

[1] SIMEONIDES (G.) - The VKI hypersonic wind tunnels and associated measurement techniques. von Karman Institute TM 46, November 1991.

[2] SIMEONIDES (G.) - Hypersonic shock wave boundary layer interactions over compression corners. Ph.D. Thesis, von Karman Institute/ University of Bristol, April 1992.

[3] VERMEULEN (J.P.), SIMEONIDES (G.) - Parametric studies of shock wave/boundary layer interactions in two-dimensional compression corners at Mach 6. von Karman Institute TN 181, September 1992.

[4] SIMEONIDES (G.), VAN LIERDE (P.), VAN DER STICHELE (S.), CAPRIOTTI (D.) and WENDT (J.F.) - Infrared thermography in blowdown and intermittent hypersonic facilities. AlAA Journal of Thermophysics and Heat Transfer, Vol. 4, No. 2, April 1990, pp. 143-148.

[5] SIMEONIDES (G.), VERMEULEN (J.P.), BOERRIGTER (H.L.) and WENDT (J.F.) - Quantitative heat transfer measurements in hypersonic wind tunnels by means of infrared thermography. IEEE Transactions on Aerospace and Electronic Systems, Vol. 29, No. 3, July 1993, pp. 878-893.

[6] SCHULTZ (D.L.) and JONES (T.V.) - Heat transfer measurements in short duration facilities. AGARDograph 165, February 1973.

[7] DE LUCA (L.) and CARDONE (G.) - Modulation transfer function cascade model for a sampled IR imaging system. Applied Optics, Vol. 30, No. 13, May 1991, pp. 1659-1664.

[8] CARLOMAGNO (G.M.) - Infrared Thermography. Lecture Series 1993-05 on Measurement Techniques, von Karman Institute, April 1993.

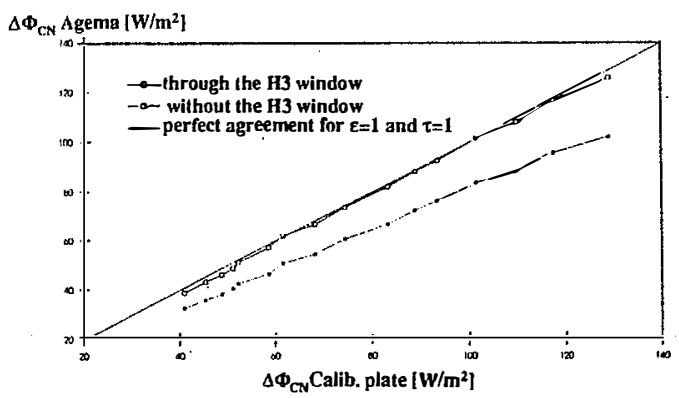

Fig.1. - Calibration of the Agema 900 system with the $20^{\circ} \times 10^{\circ}$ optics in the $\mathrm{H} 3$ hypersonic wind tunnel

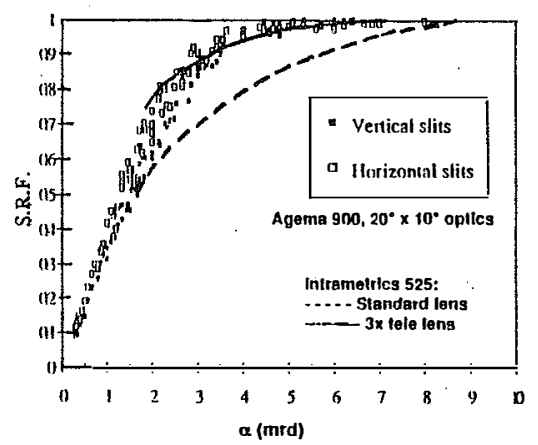

Fig.2. - Measured SRF curves for the two Infrared scanning systems 
http://dx.doi.org/10.21611/qirt.1994.025

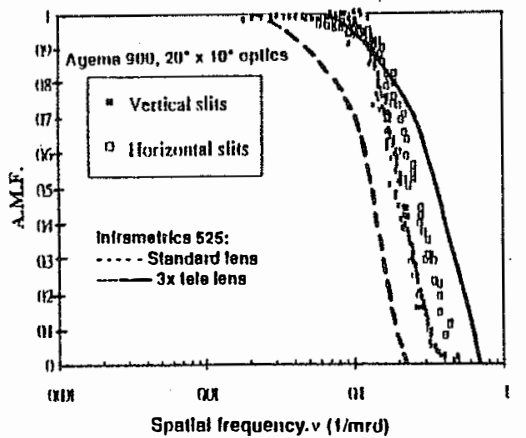

Flg.3. - Measured AMF curves for the two infrared scanning systems

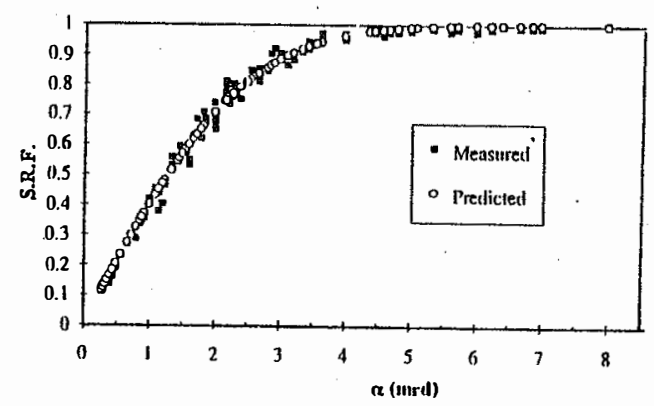

Flg.4. - Sut Response Function of the Agema 900 system for horizontal slits

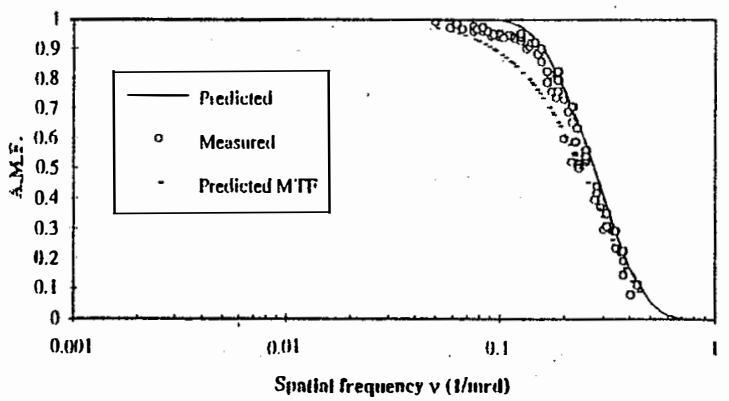

Fig.5 - AMF curves of the Agema 900 system for horizontal slits

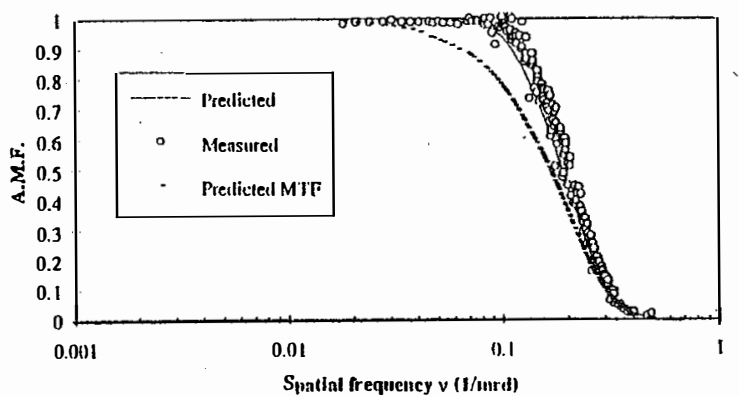

Flg.6. - AMF curves of the Agema 900 system for vertical slits

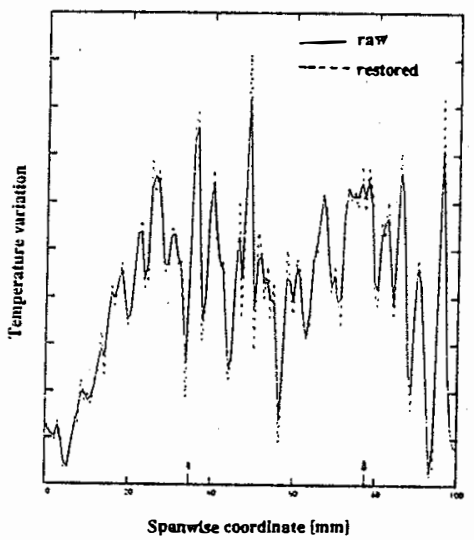

Fig. 7. - Raw and restored spanwlse temperature variations on a ramp measured with the Agema 900 system with the $20^{\circ} \times 10^{\circ}$ optics.

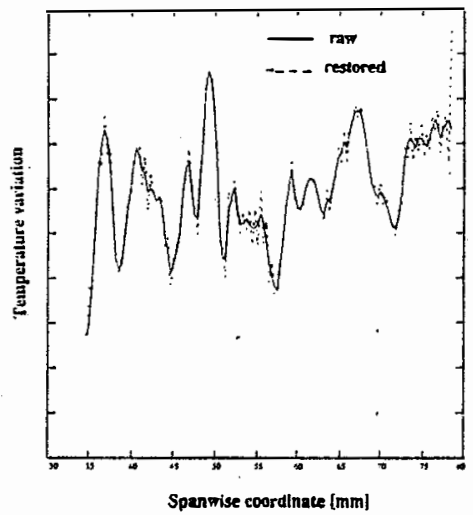

Fig. 8. - Raw and restored spanwlse temperature variations on a ramp measured with the Agema 900 system with the $10^{\circ} \times 5^{\circ}$ optics. 